\title{
$\alpha 3$, a transposable element that promotes host sexual reproduction
}

\author{
Emad Barsoum, Paula Martinez, ${ }^{1}$ and Stefan U. Åström ${ }^{2}$ \\ Department of Developmental Biology, Wennergren Institute, Stockholm University, SE-10691 Stockholm, Sweden
}

\begin{abstract}
Theoretical models predict that selfish DNA elements require host sex to persist in a population. Therefore, a transposon that induces sex would strongly favor its own spread. We demonstrate that a protein homologous to transposases, called $\alpha 3$, was essential for mating type switch in Kluyveromyces lactis. Mutational analysis showed that amino acids conserved among transposases were essential for its function. During switching, sequences in the $5^{\prime}$ and 3' flanking regions of the $\alpha 3$ gene were joined, forming a DNA circle, showing that $\alpha 3$ mobilized from the genome. The sequences encompassing the $\alpha 3$ gene circle junctions in the mating type $\alpha(M A T \alpha)$ locus were essential for switching from MAT $\alpha$ to MATa, suggesting that $\alpha 3$ mobilization was a coupled event. Switching also required a DNA-binding protein, Mating type switch 1 (Mts1), whose binding sites in MATa were important.

Expression of Mts1 was repressed in MATa/MATa diploids and by nutrients, limiting switching to haploids in lownutrient conditions. A hairpin-capped DNA double-strand break (DSB) was observed in the MATa locus in mre11 mutant strains, indicating that mating type switch was induced by MAT-specific DSBs. This study provides empirical evidence for selfish DNA promoting host sexual reproduction by mediating mating type switch.
\end{abstract}

[Keywords: Mating type switch; transposable element; gene conversion; DNA double-strand break; sexual reproduction]

Supplemental material is available at http://www.genesdev.org.

Received September 14, 2009; revised version accepted November 6, 2009.

Transposable elements (TEs) have had a profound effect on the shaping of modern genomes. In humans, close to half of the genome can be traced to TEs (Lander et al. 2001). TEs can be broadly divided into retrotransposons, which mobilize through an RNA intermediate, and DNA transposons, which mobilize through a "cut-and-paste" or "copy-and-paste" mechanism (Curcio and Derbyshire 2003). According to the parasitic DNA hypothesis, TEs are selfish DNA elements that persist in a population as a function of their ability to self-replicate (Doolittle and Sapienza 1980). The hypothesis that TEs constitute "junk" DNA that do not contribute to host fitness has been challenged (Feschotte and Pritham 2007). One example is the process of $\mathrm{V}(\mathrm{D}) \mathrm{J}$ recombination (Jones and Gellert 2004), during which the Rag1 and Rag2 proteins generate DNA double-strand breaks (DSBs) at recombination signal sequences (McBlane et al. 1995; Ramsden and Gellert 1995). RAG1 is closely related in sequence to Transib elements, a group of TEs found in different invertebrates (Kapitonov and Jurka 2005). Another example is the transposase-derived transcription factors FHY3

${ }^{1}$ Present address: Spanish National Cancer Research centre (CNIO), 28029 Madrid, Spain.

${ }^{2}$ Corresponding author.

E-MAIL stefan.astrom@devbio.su.se; FAX 46-8-6126127.

Article published online ahead of print. Article and publication date are online at http://www.genesdev.org/cgi/doi/10.1101/gad.557310. and FAR1, which regulate light signaling in Arabidopsis (Lin et al. 2007). It was suggested that FHY3 and FAR1 acquired the DNA-binding and transcriptional activation potential of transposases derived from a mutator-like TE.

Apart from $\mathrm{V}(\mathrm{D}) \mathrm{J}$ recombination, only a handful of examples are known in which programmed DSBs are induced during mitotic growth. Mating type switch in Saccharomyces cerevisiae provides such an example (Herskowitz et al. 1992; Haber 1998). Sexual differentiation in $S$. cerevisiae involves three cell types: the a-haploid and $\alpha$-haploid cell types, and the a/ $\alpha$-diploid cell type (Herskowitz 1988). In haploids, the mating type is determined by the allele present in the mating type (MAT) locus. Additional copies of a and $\alpha$ information reside at the transcriptionally silent cryptic mating type loci. A DSB induced in MAT by the HO endonuclease facilitates mating type switch through a directional gene conversion between MAT and one of the cryptic mating type loci. Mating type switch is regulated through $\mathrm{HO}$ expression, which only occurs in haploid cells during the G1 phase of the cell cycle. HO-mediated switching is restricted to the Saccharomyces sensu stricto lineage and close relatives such as Candida glabrata, Kluyveromyces delphensis, and Saccharomyces castellii (Butler et al. 2004).

Interestingly, MAT loci from different ascomycetes usually contain a conserved set of regulatory genes $(M A T \mathbf{a} 1$, $M A T \alpha 1$, and $M A T \alpha 2)$, but also genes that are not shared 
between yeasts. As an example, the high-mobility group transcription factors Mata2/Mtla2 are present in Kluyveromyces lactis and Candida albicans, where they are important for a-cell identity (Tsong et al. 2006). However, the Mata2 gene has been lost in the Saccharomyces sensu stricto group, where a-cell identity is the default state. In addition, the C. albicans MTL loci contains genes encoding poly(A) polymerases, oxysterol-binding proteins, and phosphatidylinositol kinases (Hull and Johnson 1999), seemingly without functions in mating or determination of cell type identity. The basidiomycete Cryptococcus neoformans has MAT loci spanning $>100 \mathrm{~kb}$ and encoding $>20$ genes (Lengeler et al. 2002), including mating pheromones and pheromone receptors. This acquisition of new genes in the MAT loci was suggested to resemble the evolution of sex chromosomes (Fraser et al. 2004).

$K$. lactis contains a gene in the MAT $\alpha$ locus, called $M A T \alpha 3$, that has not been found in other yeast species and whose function was unknown. In this study, we present evidence that the $\alpha 3$ protein is an ancient transposase with an essential role in mating type switching from $M A T \alpha$ to MATa. During switching, the MAT 33 gene (and $H M L \alpha 3$ ) is mobilized from the genome, forming a circular intermediate, which is similar to mobilization of some TEs (Curcio and Derbyshire 2003). We propose that adaptive evolution of a TE resulted in a novel mechanism for mating type switch in K. lactis, providing the first example of a transposon adapted to facilitate sexual reproduction.

\section{Results}

The $\alpha 3$ gene shares similarities with transposase genes

We explored mating type switching in K. lactis, a yeast species lacking a functional $H O$ gene (Fabre et al. 2005). $K$. lactis contains a duplicated gene in the $H M L \alpha$ and $M A T \alpha$ loci, $\alpha 3$, that has not been found in other yeast species. Position-specific iterated (PSI) BLAST (Altschul et al. 1997) searches revealed significant homology between $\alpha 3$ and transposases of the mutator-like (MULE) family (Fig. 1A) from plants, but also uncharacterized ORFs from other organisms (Supplemental Material). The analysis revealed the presence of three different protein domains constituting signature motifs of MULE transposases in $\alpha 3$ (Juretic et al. 2005; Babu et al. 2006). We compared the $H M L \alpha$ locus from $K$. lactis with the corresponding loci in other ascomycetes using the yeast gene order browser (Byrne and Wolfe 2005). Compared with the $H M L \alpha$ loci in S. cerevisiae and C. glabrata, the genes surrounding $H M L \alpha 3$, as well as their transcriptional orientation, were conserved. However, only K. lactis contained the $H M L \alpha 3$ gene (Fig. 1B). This result, together with the homology with transposases, suggested that the $H M L \alpha 3$ gene originated from a horizontal gene transfer of a TE.

Isolation of strains overexpressing Mating type switch 1 (Mts1) in a selection for defective silencing

We hypothesized that $\alpha 3$ was involved in mating type switch in K. lactis, but since our laboratory strains
A

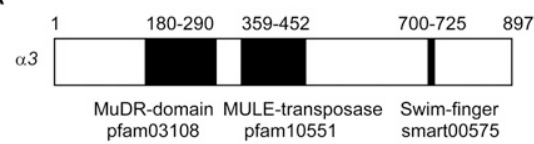

B

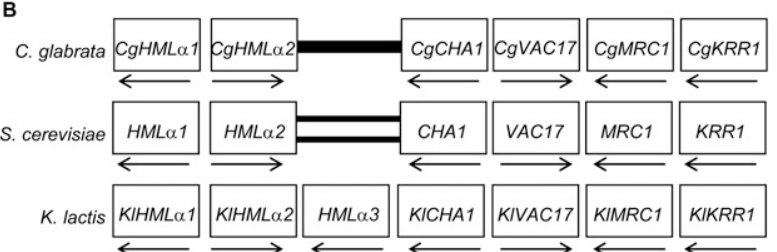

C
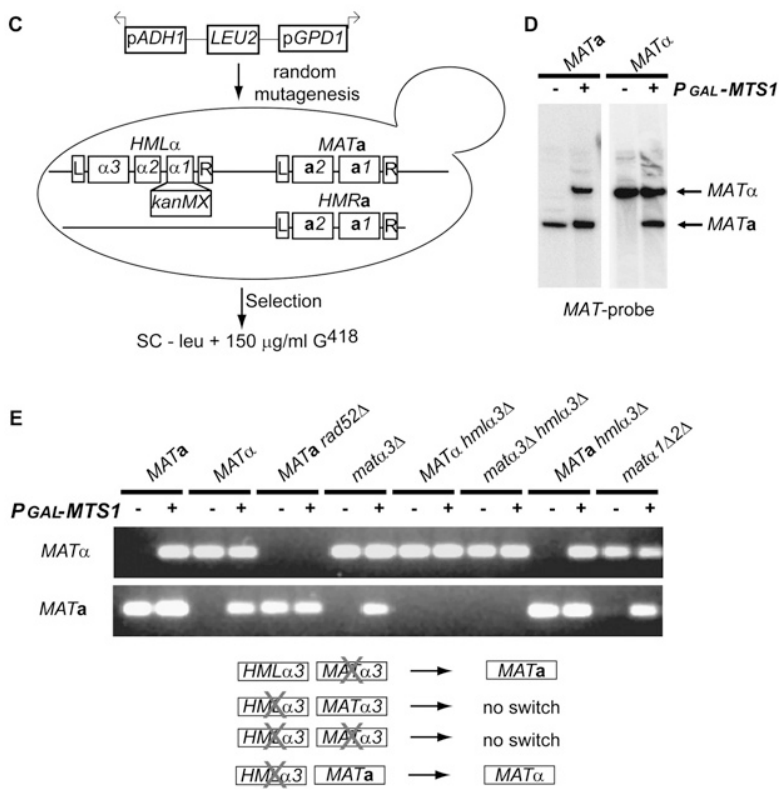

Figure 1. The $\alpha 3$ gene encoded a putative transposase essential for mating type switch. (A) Schematic drawing of the $\alpha 3$ ORF, indicating the relative positions of protein domains. $(B)$ A synteny view of the $H M L \alpha$ loci from C. glabrata, S. cerevisiae, and $K$. lactis. Boxes denote genes, and boxes in the same column are orthologs. The gene names for the S. cerevisiae genes are indicated, as well as the transcriptional orientation of the genes (arrows). A thick bar indicates a lack of an ortholog. The double bars indicate lack of an ortholog and an inversion relative to the other genes. $(C)$ Schematic representation of the genetic selection. SAY130 (hml $1 \Delta:: k a n M X)$ was mutagenized with pRS405pApG. The genes within the MATa, $H M R \mathbf{a}$, and $H M L \alpha$ loci are depicted, including the shared flanking repeats $\mathrm{L}$ and $\mathrm{R}$. De-

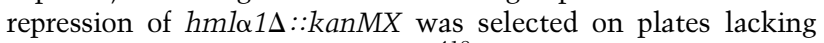
leucine, containing $150 \mu \mathrm{g} / \mathrm{mL} \mathrm{G}^{418}$. (D) DNA blot analysis of BamHI-digested DNA from SAY45 (MATa) and SAY119 (MAT $\alpha)$ containing pGAL-MTS1 (+) or plasmid alone $(-)$, hybridized with a MAT-specific probe. The MATa and MAT $\alpha$ bands are indicated. (E, top panel) PCR analysis of mating type switch in SAY45

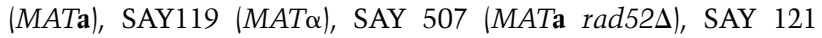

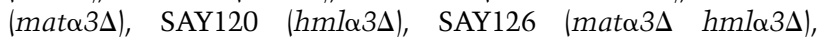
SAY122 (MATa hml $33 \Delta)$, and SAY688 (mat $1 \Delta \alpha 2 \Delta)$. Genomic DNA from these strains containing either the pGAL-MTS1 plasmid $(+)$ or the empty vector $(-)$ were subjected to MATa and $M A T \alpha$-specific PCR, and the resulting products were resolved on agarose gels. (Bottom panel) Schematic drawing of the $\alpha 3$ mutant strains indicating if they switched mating type. 
switched mating type very rarely, we had to develop an assay to test this notion. This was accomplished by using a genetic selection. This selection (aimed at identifying genes involved in transcriptional silencing) used a strain containing a silenced hml $1 \Delta::$ kanMX gene. The strain was mutagenized with linear DNA, taking advantage of the high illegitimate recombination frequency displayed by $K$. lactis (Kegel et al. 2006), selecting for $\mathrm{G}^{418}$ resistance (Fig. 1C; see the Materials and Methods for details). We used a plasmid containing a selectable marker (LEU2) flanked by strong promoters (GPD1 and $A D H 1$ ) oriented in opposite directions. By linearizing the plasmid in between the two promoters prior to transformation, the insertion of the plasmid into the genome by illegitimate recombination was expected to cause strong outwarddirected transcription. Among the $\mathrm{G}^{418}$-resistant strains recovered were three independent isolates that contained insertions in the same intergenic region (see the Materials and Methods). These insertions resulted in overexpression of the gene adjacent to the insertion (data not shown). This gene was the ortholog of $S$. cerevisiae RME1, a transcriptional regulator. The similarity between the predicted amino acid sequence of this protein and Rmel was confined to the C-terminal domain containing three zinc finger motifs (Supplemental Fig. S1). We named this gene MTS1 since overexpression of this gene induced efficient switching in K. lactis (Fig. 1D). This result indicated that the retrieval of the Mts1-overexpressing mutants in the genetic selection was due to a physical translocation of the silenced kanMX gene into the expressed MAT locus, rather than an effect on transcriptional silencing.

\section{HML $\alpha 3$ was necessary for MAT $\alpha$-to-MATa switching}

To investigate whether the $\alpha 3$ gene controlled mating type switch, we assayed switching in a set of K. lactis strains that harbored deletions in the HML 3 and/or MAT 33 genes. The strains contained a plasmid carrying MTS1 under the control of a strong GAL1 promoter to induce switching, or the empty plasmid as control. Switching events were detected by PCR amplification of the MATa or $M A T \alpha$ loci (see the Materials and Methods). This assay worked reliably, as wild-type MATa or MAT $\alpha$ strains showed Mts1-dependent switching (Fig. 1E), but a MATa rad52 mutant strain did not, since Rad52 is essential for gene conversion (Malone and Esposito 1980). The $\alpha 1$ and $\alpha 2$ proteins are expressed only from the MAT $\alpha$ locus and were not required for mating type switch, since a mutation that removed most of these ORFs, including their common promoter region, switched mating type. We tested switching in two single-mutant strains (mata3 $H M L \alpha 3$

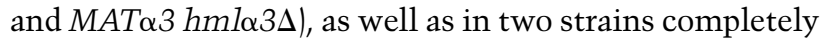
lacking $\alpha 3$ coding sequences (MATa hml 33 and mat $\alpha 3 \Delta$ $h m l \alpha 3 \Delta)$. Both the MAT $\alpha$ and the mat $3 \Delta$ strains containing the hmla $3 \Delta$ mutation did not switch mating type. However, the mat $3 \Delta H M L \alpha 3$ and MATa hml $3 \Delta$ strains switched mating type (Fig. 1E). This showed that $H M L \alpha 3$ was required for switching from MAT $\alpha$ to MATa, but not from MATa to MAT $\alpha$. As $H M L \alpha 3$ and MAT $\alpha 3$ encode identical proteins, the unique dependence on $H M L \alpha 3$ was surprising, and was confirmed on a DNA blot (Supplemental Fig. S2). Importantly, a plasmid-borne GFP- $\alpha 3 \mathrm{fu}-$ sion gene could complement the switching defect of a

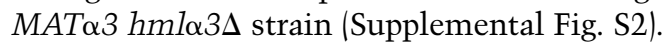

\section{Mts1 binds to both the MATa and MAT $\alpha$ loci}

To begin exploring cis-acting sequences in the MATa locus that were necessary for switching, we generated three mutant strains. The mata $\Delta$ strain had the entire locus deleted except for the flanking sequences called L (left) and $\mathrm{R}$ (right). The $\mathrm{L}$ and $\mathrm{R}$ sequences are shared between all mating type loci and presumably are used as blocks of homology to resolve recombination intermediates. The genes encoded by the MATa locus were deleted individually in two separate strains, generating mata $1 \Delta$ and mata2 $\Delta$ strains, respectively. Overexpression of MTS1 in these strains demonstrated that the mata $\Delta$ strain did not switch mating type, whereas the mata1s and mata2s strains did (Fig. 2A). This indicated that the intergenic sequence in between MATa1 and MATa2 was essential for switching, but that the a1 and a 2 gene products were dispensable.

This result prompted us to screen the 855-base-pair (bp)-long MATa1 and MATa2 intergenic region for Mts1binding sites. Seven DNA probes spanning this region were tested for binding to recombinant Mts1 using an electrophoretic mobility shift assay (EMSA) (Supplemental Fig. S3). Two of the probes showed specific mobility shifts (Fig. 2B). Using the DNA fragment showing the most robust mobility shift and competitor DNA, we pinpointed one Mts1-binding site to 111-129 bp upstream of the start codon of MATa2 (Fig. 2C). Examination of this 19-bp sequence revealed the presence of a close match to the previously described $S$. cerevisiae Rmel-binding site (Shimizu et al. 1998). Three similar sites were found within the other probe originating from the MATa1 and MATa2 intergenic region that showed a mobility shift. Interestingly, two closely juxtaposed copies of a very similar sequence were also found upstream of the $M A T \alpha 3$ gene close to the $\mathrm{L}$ repeat (Fig. 2C). We used 19-bp duplexes corresponding to the site upstream of MATa2 and one of the MAT $\alpha$ sites as competitors for the Mts1 mobility shift. Only 2 pmol of a sequence originating from the $\alpha 3$ upstream region abolished the mobility shift (Fig. 2D). For the sequence from the a 2 upstream region, 25 pmol were required for efficient competition. In both cases, we used duplexes with 2 bp changed, compared with the genomic sequence as controls. Both competed very inefficiently for the Mts1 mobility shift (Fig. 2D).

\section{Deletion of Mts1-binding sites reduced switching from MAT $\alpha$ to MATa}

Next, we investigated whether the Mts1-binding sites in the MAT $\alpha$ locus were important for switching. We introduced a 20-bp deletion close to the $\mathrm{L}$ repeat in the $M A T \alpha$ locus $($ mat $\alpha \Delta 20)$, which deleted the two closely juxtaposed putative Mts1-binding sites shown in Figure 2C. Two independent isolates were transformed with either pGAL-MTS1 plasmid or empty vector, and the 
A

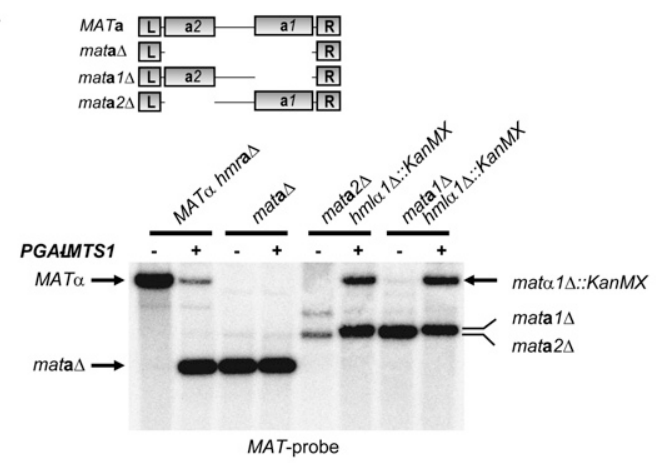

B

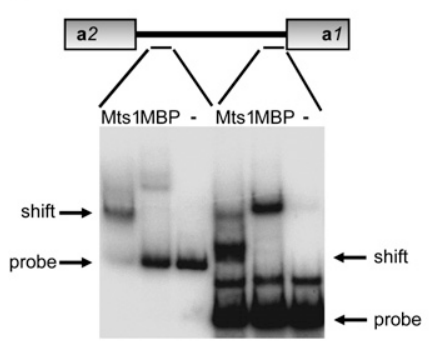

C GWACCTCAARA

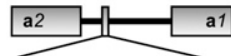
1 CAAATTACCTCAAAAAAAA CAAATTAAATCAAAAAAAA 2 GTTTAaTTIATTTTTTTT

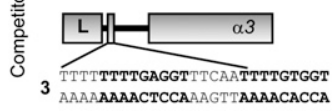
4 TTTTTTTTGATTTTTCAAT

D

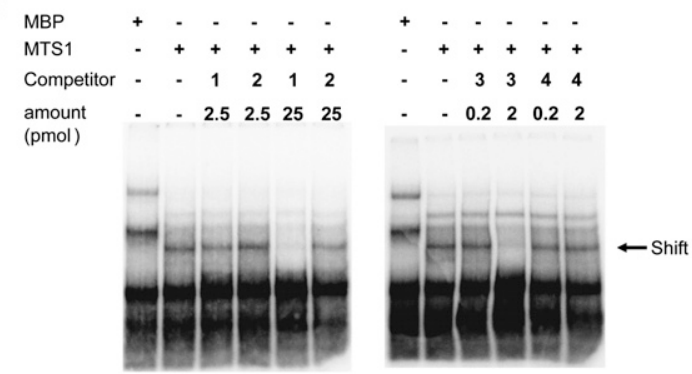

Figure 2. Identification of Mts1-binding sites in both the MATa and $M A T \alpha$ loci. (A, top panel) Schematic drawing showing the deletions generated in the MATa locus. (Bottom panel) DNA blot

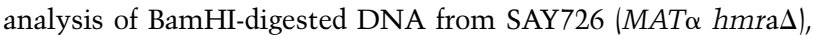

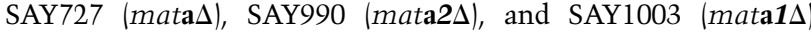
containing pGAL-MTS1 (+) or plasmid alone (-). A MAT-specific probe was used, and the identity of the bands is shown. (B) EMSA using probes from the MATa1-MATa2 intergenic region. Either recombinant Mts1, maltose-binding protein (MBP), or no protein (-) was added to the probes prior to electrophoresis. The location of the free probes and Mts1-dependent mobility shifts are indicated. $(C)$ Drawing of the location of the Mts1-binding sites in the MATa and MAT $\alpha$ loci. The DNA sequence of the 19-bp duplexes (1-4) used as competitors in $D$ is shown. Note the second potential binding site at MAT $\alpha$ (competitor 3), which was not included on the competing fragment. (Top) The Rme1binding site in $S$. cerevisiae is shown. (W) A or T; (R) A or G. $(D)$ EMSA using the probe on the left in $B$, but also including competitor duplexes with the sequences shown in $C$. Competitors used and their concentrations are indicated above the lanes.

mating type switch was scored by genomic DNA blot. The strains harboring the deletion displayed a severe reduction in switching (Fig. 3). Compared with the wild type with a MATa/MAT $\alpha$ ratio of 0.38 , two isolates of the isogenic mutant strains had ratios of 0.13 and 0.08 , respectively. Hence, deletion of these Mts1-binding sites reduced switching by a factor of 3-5. Deleting only one of the Mts1-binding sites in MAT $\alpha$ had no effect on switching (data not shown). We concluded that Mts1 had a direct role in mating type switch by binding to distinct binding sites in the MAT $\alpha$ locus. It should be pointed out that the defective switching observed in the mat $\alpha 20$ strain cannot be a consequence of a decreased expression of the

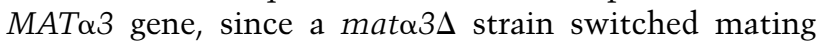
type with normal efficiency (Supplemental Fig. S2).

\section{MTS1 expression was regulated by nutrients and cell type}

It was observed previously that switch of the mating type in K. lactis did not occur until cells were transferred to malt extract (ME) medium (Herman and Roman 1966), a nutrient-limited medium. To determine if the transcription of MTS1 was different in nutrient-rich (YPD) and synthetic (SC) medium, we measured transcript levels from MATa wild-type cells grown in SC, YPD, and $0.5 \times$ SC/YPD using either glucose or galactose as a carbon source. The MTS1 transcript was approximately sixfold more abundant in SC compared with YPD or $0.5 \times \mathrm{SC} /$ YPD (Fig. 4A), but the carbon source had only minor effects. Since mixing rich medium with synthetic medium $(0.5 \times \mathrm{SC} / \mathrm{YPD})$ led to low expression levels, the rich medium appeared to have a dominant repressing effect.

The fact that MTS1 transcription was also repressed in a MATa/MATa diploid grown in SC medium (Fig. 4A) indicated that an additional repression mechanism was controlling MTS1 expression. To distinguish between ploidy effects and the possibility that MTS1 was repressed by the diploid-specific a1 $/ \alpha 2$ repressor, we investigated MTS1 transcription in a MATa sir2 and a MATa sir2 $h m l \alpha \Delta p$ background. In a MATa sir2 strain, MTS1 transcription was repressed. This repression was alleviated by the $h m l \alpha \Delta p$ mutation that abolishes transcription of the $H M L \alpha 1$ and $H M L \alpha 2$ genes (Fig. 4A, right panel). Therefore, MTS1 transcription was regulated by cell type, likely through the a1 $/ \alpha 2$ repressor.

A strain containing a MTS1-TAP fusion gene was generated, and we measured the steady-state levels of

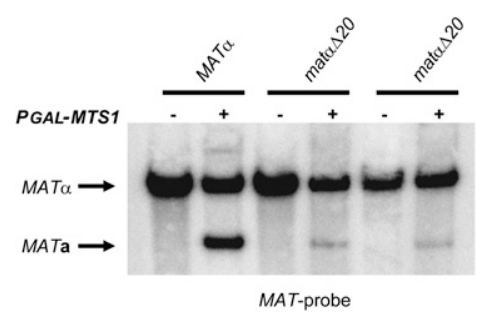

Figure 3. Mts1-binding sites in the MAT $\alpha$ locus were important for efficient mating type switch. DNA blot analysis using

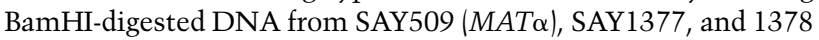
(both mat $\alpha 20$, deleting the two putative Mts1-binding sites shown in Fig. 2C), containing pGAL-MTS1 (+) or plasmid alone $(-)$. A MAT-specific probe was used, and the identity of the bands is shown. 
A

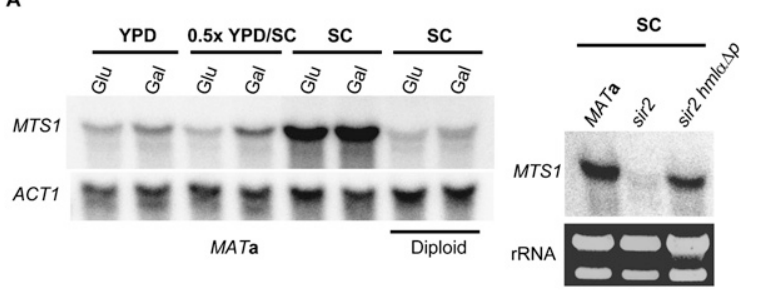

B

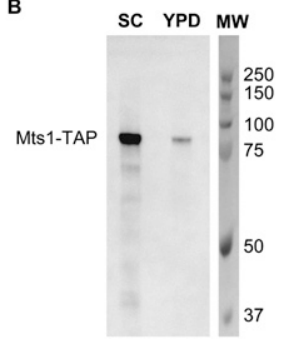

Figure 4. Mts1 expression was regulated by nutrients and cell type. (A, left panel) RNA blot analysis using total RNA from SAY45 and SAY45 $\times$ SAY119 (diploid) as indicated below the blot. Cells were grown in YPD, SC, or $0.5 \times \mathrm{YPD} / \mathrm{SC}$ using either glucose (glu) or galactose (gal) as a carbon source. The blot was hybridized with an MTS1-specific probe, stripped, and rehybridized with an ACT1-specific probe as a loading control. (Right panel) RNA blot analysis using total RNA from SAY45, SAY102 $(\operatorname{sir} 2 \Delta)$, and SAY189 $(\operatorname{sir} 2 \Delta \mathrm{hml} \alpha \Delta p)$. Cells were grown in SC medium and the blot was hybridized with an MTS1-specific probe. As loading control, rRNA bands from the same strains are shown. (B) Protein blot analysis of total proteins $\left(0.1 \mathrm{~A}_{600}\right)$ from SAY988 (MTS1-TAP) grown in either SC or YPD. Anti-TAP (Invitrogen) was used as the primary antibody. Molecular weight markers (MW) are shown on the right.

Mts1-TAP in cells grown in YPD and SC using an antiTAP antibody. Consistent with the RNA blot, we found sevenfold higher levels of Mts1-TAP in cells grown in SC (Fig. 4B) compared with YPD.

\section{$\alpha 3$ mobilized from the genome in response to Mts1 overexpression}

Next, we explored if the $\alpha 3$ gene had other features in common with TEs. Figure 5A schematically shows the $M A T \alpha / H M L \alpha$ loci, displaying the three ORFs as well as the flanking sequences $\mathrm{L}$ and $\mathrm{R}$. DNA blotting of $M A T \alpha$ strains overexpressing Mts1 revealed a band (Fig. 5B) that hybridized to an $\alpha 3$-specific probe (Fig. 5A), which could not be explained as a linear DNA fragment based on the positions of restriction enzyme sites. We hypothesized that this band could represent a circular DNA molecule. To test this, we performed inverse PCR on genomic DNA from strains overexpressing Mts1 using two different primer pairs that could only render a product if a circular DNA molecule was present (Fig. 5C). A PCR product was readily observed. DNA sequencing revealed that the band corresponded to an $\alpha 3$ gene fragment in which the $5^{\prime}$ and 3 ' ends were fused. Thus, the band observed on the DNA blot (Fig. 5B) corresponds to a head-to-tail fusion of the $\alpha 3$ gene (the band is missing an internal $\mathrm{XbaI}$ fragment in this $\mathrm{XbaI}$ digest). To confirm the presence of a circular form of $\alpha 3$, we treated BamHI-digested genomic DNA (there are no BamHI sites in the circle) with $\lambda$-exonuclease, which specifically degrades linear DNA but not circles or nicked circles. The results showed that a linear $M A T \alpha$ fragment was sensitive to the exonuclease, but a putative supercoiled and relaxed form of the $\alpha 3$ circle was resistant (Fig. 5D). Thus, $\alpha 3$ retained the ability to

A
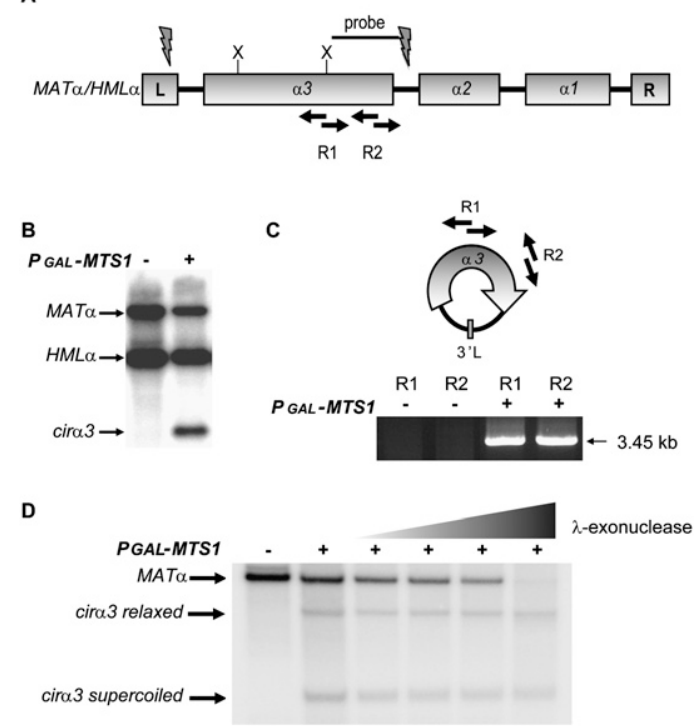

E

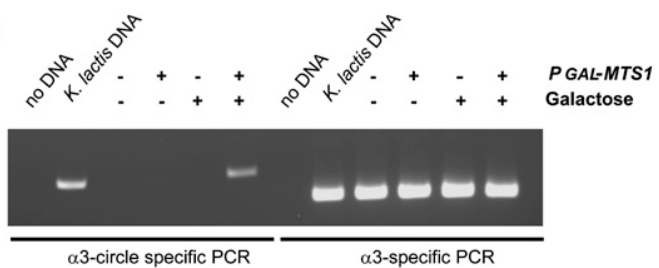

Figure 5. The $\alpha 3$ gene mobilized from the genome. (A) Schematic drawing of the $M A T \alpha / H M L \alpha$ loci. The position of the probe used in $B$, the positions of the PCR primers used in $C$, and $\mathrm{XbaI}$ sites are indicated. The flashes indicate where the $\alpha 3$ gene circle is joined. $(B)$ DNA blot analysis of XbaI-digested DNA from SAY119 $(M A T \alpha)$ containing pGAL-MTS1 (+) or plasmid alone (-) hybridized with the probe indicated in $A$. The $M A T \alpha, H M L \alpha$, and cira3 bands are indicated. (C, top panel) Inverse PCR strategy used to reveal the nature of the cira3 band. (Bottom panel) Genomic DNA from strain SAY119 containing pGAL-MTS1 (+) or plasmid alone was subjected to inverse PCR using the primer pairs R1 and R2, followed by agarose gel electrophoresis. (D) DNA blot analysis of BamHI-digested DNA from SAY119 $(M A T \alpha)$, containing vector alone $(-)$ or $\mathrm{p} G A L-M T S 1(+)$. Lanes 3-6 were treated with increasing concentrations of $\lambda$-exonuclease $(0.02,0.1,0.5$, and $2.5 \mathrm{U}$, respectively). The identity of the bands hybridizing to the $\alpha 3$-specific probe is shown beside the blots. $(E)$ S. cerevisiae strain SAY73 containing K. lactis HML (M plasmid) was subjected to $\alpha 3$ circle-specific PCR and $\alpha 3$ gene-specific $\mathrm{PCR}$, followed by agarose gel electrophoresis, as indicated. In addition, either pRS414 without insert (-) or pRS414-pGALMTS1 (+) was introduced and grown in the presence of glucose $(-)$ or galactose $(+)$, as indicated. As controls, no DNA lanes and $K$. lactis DNA lanes were included. 
excise from the genome in a manner similar to many TEs. It should be pointed out that, on DNA blots, the hybridization signal from the novel band was stronger in MATa strains than in MATa strains (data not shown). Hence, most of the signal originated from the MATa locus, although some of it originated from the $H M L \alpha$ locus. To learn more about the formation of the $\alpha 3$, circle we tested whether it could be induced ectopically in $S$. cerevisiae. A plasmid containing the entire K. lactis $H M L \alpha$ locus was introduced into a wild-type $S$. cerevisiae strain. Then we introduced either plasmid alone or the pGAL-MTS1 vector. Circle-specific PCR showed that the $\alpha 3$ circle was formed in S. cerevisiae in an MTS1-dependent manner (Fig. 5E). Thus, the only K. lactis-specific loci required for circle formation were MTS1 and $H M L \alpha$. Notably, circularization is a feature of several TEs (Curcio and Derbyshire 2003) and may be a characteristic of the mutator elements in maize (Sundaresan and Freeling 1987), but is almost unheard of for nontransposable genes.

\section{Mutations in the DDE motif and SWIM finger of $\alpha 3$ abolished switching}

To confirm that $\alpha 3$ indeed was required for switching, we

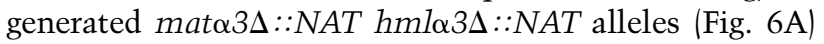
that were complete null alleles flush from the start codon to the stop codon. Then, we introduced a plasmid expressing a GFP- $\alpha 3$ fusion gene controlled by the GPD1 promoter. A pGAL-MTS1 plasmid was introduced simultaneously, and we tested whether the strains switched mating type. The results in Figure 6B show that the GFP- $\alpha 3$ fusion gene could complement the switching defect of the mat $33 \Delta$ hmla $3 \Delta$ strain. In the absence of pGAL-MTS1, we observed low-level background switching due to the endogenous MTS1 gene, which is induced in the synthetic growth medium used in this experiment (Fig. 4). To begin characterizing which features of $\alpha 3$ were important for function, we generated mutations in GFP- $\alpha 3$. Multiple sequence alignments with $\alpha 3$ and known mutator transposases are difficult to assemble due to low sequence similarity. However, comparing $\alpha 3$ with the plant transposasederived protein FAR1 by PSI-BLAST (Supplemental Fig. S4; Lin et al. 2007) predicted that D363 and D424 were part of the catalytic DDE motif. The DDE motif is required for coordination of metal ions in many transposases (Kulkosky et al. 1992; Haren et al. 1999). The position of the " $\mathrm{E}$ " residue was ambiguous, but the glutamate in position 505 of $\alpha 3$ aligned with a glutamate in FAR1. We therefore generated $\alpha 3 D 363 A, \alpha 3 D 424 A$, and $\alpha 3 E 505 A$ alleles. The other allele tested exchanged two of the cysteines in the SWIM finger for alanine residues $(\alpha 3 C 702)$ $704 A$ ). The only mutant $\alpha 3$ protein that complemented the switching defect was $\alpha 3$ E505A (Fig. 6B). By performing protein blots using an anti-GFP antiserum, we showed that all fusion proteins were present at similar steady-state levels (Fig. 6C). D363, D424, and the SWIM finger of $\alpha 3$ were therefore essential for the mating type switch from $M A T \alpha$ to MATa. To investigate whether the formation of the $\alpha 3$ gene circle had the same molecular requirements as the mating type switch, we stripped the blots used in
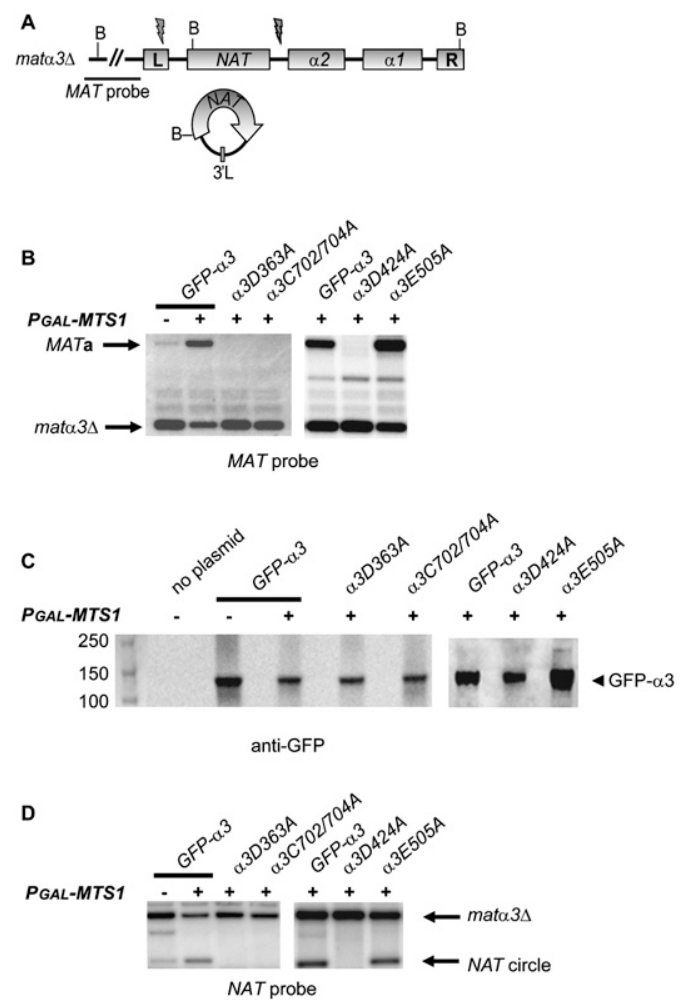

Figure 6. Mutations in the DDE motif and the SWIM finger of $\alpha 3$ abolished mating type switch. (A) Schematic drawing of the mata3 $3:: N A T$ locus with the location of BamHI sites shown. The location of the MAT probe is indicated. Flashes indicate where the $\alpha 3$ gene circle is joined, and below is a drawing of the resulting NAT-containing circle. (B) DNA blot analysis of BamHI-digested genomic DNA from strain SAY1356 (mata3A $h m l \alpha 3 \Delta$ ) containing a plasmid with a GFP- $\alpha 3$ gene fusion and mutant derivatives, as indicated. The strains contained either pGAL-MTS1 (+) or the empty vector (-). A MAT-specific probe was used, and the MATa and mat $\alpha 3 \Delta$ bands are indicated. $(C)$ Shown is a protein blot using an $\alpha$-GFP antibody against GFP$\alpha 3$. Total protein $\left(0.1 \mathrm{~A}_{600}\right)$ prepared from cells expressing wildtype or mutant GFP- $\alpha 3$, as indicated, was subjected to electrophoresis and blotting. A strain lacking the GFP- $\alpha 3$ plasmid shows that the antibody was specific. Molecular weight markers in kilodaltons are shown on the left. $(D)$ The same blots as in $B$, but hybridized with a NAT-specific probe. The probe detects both a mat $33 \Delta:: N A T / h m l \alpha 3 \Delta:: N A T$-specific band and a $N A T$ circle with $\alpha 3$ flanking sequences, as indicated.

Figure $6 \mathrm{~B}$ and reprobed with a NAT probe. If the formation of the circle required the $\alpha 3$ protein, then we expected to generate a NAT-containing circle with $\alpha 3$ flanking sequences only when a functional $\alpha 3$ allele was present. The results were completely consistent with this notion (Fig. 6D). Thus, the $\alpha 3$ protein was required for excising the $\alpha 3$ gene from the genome.

\section{The sequences at the MAT $\alpha 3$ circle junction were required for switching from MAT $\alpha$ to MATa}

Next, we investigated the role of the DNA sequences encompassing the circle junctions, both for mating type switching and for formation of the $\alpha 3$ gene circle. 
Sequencing the $\alpha 3$ circle junction revealed that the fusion took place at a TA sequence, the $5^{\prime}$ junction resided within the L repeat, and the $3^{\prime}$ junction was in the $\alpha 3-\alpha 2$ intergenic region (Fig. 7A). The $5^{\prime}$ junction sequence had an 11-bp inverted repeat immediately downstream from the TA sequence. In addition, there were other sequences shared between the $5^{\prime}$ and 3' junctions (see Fig. 7A). First, we investigated the importance of these sequences at $H M L \alpha$ by generating strains with deletions of the $5^{\prime}$ junction $\left(h m l \alpha 3 \Delta 5^{\prime}\right)$ or the $3^{\prime}$ junction $\left(h m l \alpha 3 \Delta 3^{\prime}\right)$. Overexpressing Mts 1 in a MATa hml $\alpha \Delta 3^{\prime}$ strain did not result in $\alpha 3$ circle formation, showing that the sequences at the 3 ' junction were essential. Strikingly, deletion of the 5' junction resulted in a novel circle junction. This novel junction also occurred at a TA sequence, and the distance with respect to the $\alpha 3$ ORF was maintained (Fig. 7B). Hence, the sequence spanning the $5^{\prime}$ circle junction in
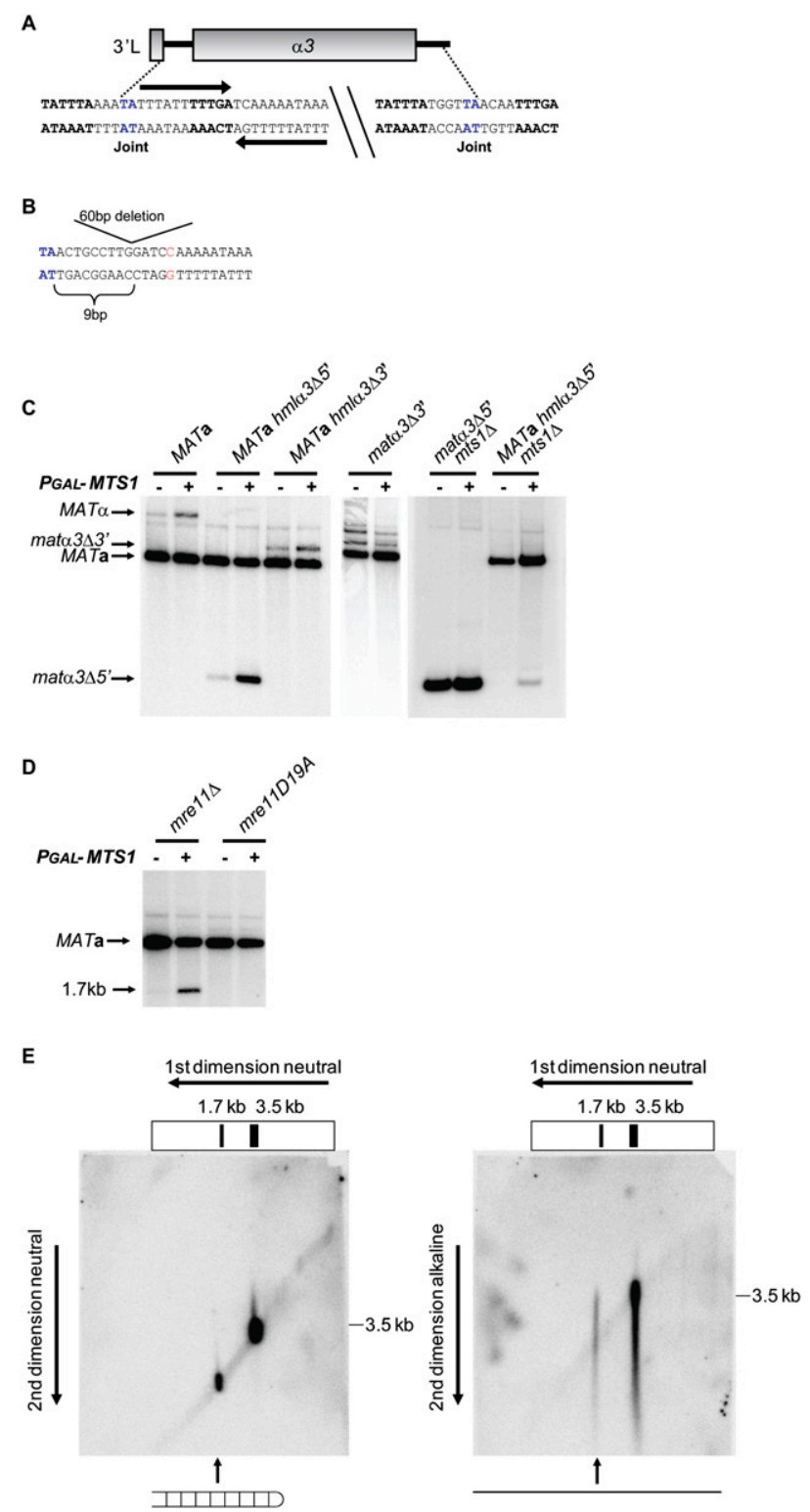

wild-type strains was not essential for excising the $H M L \alpha 3$ gene.

Then, we explored the relationship between circle formation and mating type switching. We investigated switching in MATa hml $3 \Delta 5^{\prime}$ and MATa hml $3 \Delta 3^{\prime}$ strains and found that both strains switched their mating type (Fig. 7C).

We noticed low levels of switching in the absence of Mts1 overexpression (Fig. 7C). To test whether the endogenous MTS1 gene mediated this switch, we explored

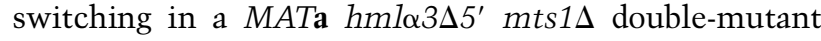
strain. Removing the endogenous MTS1 gene abolished background switching, which could be rescued by introduction of the pGAL-MTS1 plasmid. Hence, endogenous levels of MTS1 could mediate mating type switch.

Next, we investigated the importance of the circle junction sequences at the MAT $\alpha$ locus. We thus generated mat $\alpha 3 \Delta 5^{\prime}$ mts $1 \Delta$ and mat $\alpha 3 \Delta 3^{\prime}$ mutant strains. Overexpression of Mts1 in these strains showed that neither of them switched their mating type to MATa (Fig. 7C). Thus, the circle junction sequences were essential for switching when present at $M A T \alpha$. Consequently, for switching from $M A T \alpha$ to $M A T \mathbf{a}$, generating a MAT-derived normal $\alpha 3$ circle was essential. These observations strongly suggested that, for switching from MAT $\alpha$ to MATa, the DNA lesions generated during $M A T \alpha 3$ excision were essential switching intermediates.

Figure 7. Switching from MAT $\alpha$ to MATa required the sequences spanning the MAT $\alpha 3$ circle junctions and formation of DNA hairpins in the MATa locus. (A) Schematic drawing of the DNA sequences spanning the $\alpha 3$ circle junctions. The TA sequence in blue indicates the fusion point, bases in bold indicate sequences shared between the $5^{\prime}$ and $3^{\prime}$ circle junctions, and arrows show a 22-bp inverted repeat. (B) A 60-bp deletion $\left(5^{\prime}\right.$ junction sequence) and a 26-bp deletion ( $3^{\prime}$ junction sequence) were introduced in $H M L \alpha$, resulting in either a novel circle junction or no circle formation, respectively. Shown is the novel circle junction generated in the hml $\alpha 3 \Delta 5^{\prime}$ mutant. Note the 9-bp spacing from the start of the deletion to a novel fusion point, which was the same spacing as in the wild-type junction. For cloning purposes, a C (red) was introduced in the 60-bp deletion of the $5^{\prime}$ junction sequence. $(C)$ DNA blot analysis using BamHIdigested DNA from SAY45 (MATa), SAY875 (MATa hmla3A5'),

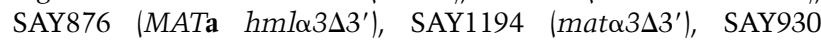

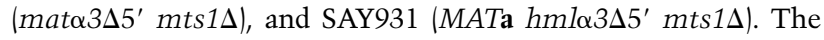
strains contained either pGAL-MTS1 (+) or plasmid alone (-). A $M A T$-specific probe was used, and the identity of the bands is indicated. $(D)$ DNA blot analysis using BamHI-digested DNA from SAY559 (MATa mre11D) and SAY973 (MATa mre11-D19A) containing pGAL-MTS1 (+) or plasmid alone (-). A MAT-specific probe was used, and the identity of the bands hybridizing to the probe is shown beside the blot. (E) Two-dimensional gel electrophoresis followed by hybridization to a MAT-specific probe. (Left panel) Both dimensions were performed under neutral conditions (1× TAE). (Right panel) The first dimension was performed under neutral conditions, and the second dimension was performed under denaturing conditions ( $30 \mathrm{mM} \mathrm{NaOH}, 0.1 \mathrm{mM}$ EDTA). The size of a $3.5-\mathrm{kb}$ marker in the second dimension is shown on the left of both panels. Indicated below the panels is the duplex versus ssDNA nature of the hairpin DNA intermediate. 


\section{Formation of a hairpin-capped DSB at MATa}

We tested the trans-acting molecular requirements for switching. In both MATa and MAT $\alpha$ strains, several genes known to mediate gene conversion were essential for switching (data not shown). A MATa mre11D strain did not undergo switching (Fig. 7D), but surprisingly, a novel faster migrating band hybridizing to the MAT-specific probe was observed. We hypothesized that this band represented a switching intermediate that was stabilized in mre $11 \Delta$ strains. The size of the band $(1.7 \mathrm{~kb})$ indicated the presence of a DSB in the MATa1-MATa2 intergenic region. An allele carrying a point mutation, mre11D19A, corresponding to the mre11D16A allele in S. cerevisiae, was generated. Mre11D16A was shown previously to be strongly compromised for Mre11 exonuclease activity (Lewis et al. 2004). The mre11D19A strain neither switched mating type nor generated the intermediate seen in the mre $11 \Delta$ strain. Hence, the Mre11 exonuclease activity was required for completing the switch, but lack of it was not sufficient for stabilizing the intermediate.

Based on previous studies that showed a requirement for Mre11 in opening hairpins (Paull and Gellert 1998; Trujillo and Sung 2001), we hypothesized that the intermediate observed in the mre11 $1 \Delta$ strain could be a DNA hairpin. To test this notion, we performed two-dimensional gel electrophoresis (Fig. 7E). The first dimension was performed under neutral conditions. Gel slices were cut from the lanes, turned perpendicular, and subjected to second-dimension electrophoresis under either neutral or alkaline conditions. Neutral/neutral electrophoresis generated the expected size pattern of $3.5-\mathrm{kb}$ and $1.7-\mathrm{kb}$ duplexes. When the second dimension was performed under alkaline conditions, the $1.7-\mathrm{kb}$ duplex gave rise to a band that migrated as an $\sim 3.4-\mathrm{kb}$, ssDNA molecule (Fig. $7 \mathrm{E})$. The $3.5-\mathrm{kb}$ band gave rise to the expected $3.5-\mathrm{kb}$ single-stranded band on the alkaline blot. This result indicated that the DSB observed in the mre11 strain terminated in a DNA hairpin. We also used a probe that hybridized to the distal side of the DSB in the mre11s strain, which likewise revealed the presence of a DNA hairpin (data not shown). We concluded that, during $M A T$ a to MAT $\alpha$ switching, a hairpin-capped DSB was generated in the MATa locus.

\section{Discussion}

\section{Evolution of mating type switching in ascomycetes}

Here, we demonstrate a novel mechanism for mating type switching in K. lactis, which is induced by a DNA-binding protein (Mts1) and requires a transposase-like protein ( $\alpha 3)$. Given that K. lactis contains an $\mathrm{HO}$ pseudogene (Fabre et al. 2005), it seems likely that an HO-mediated switching mechanism was the ancestral state and that the MTS1/ $\alpha 3$-mediated mechanism described here arose later. This prediction is at odds with a previous study (Butler et al. 2004) that suggested that the $H O$ gene arose after $S$. cerevisiae and K. lactis diverged from each other. At that time, however, the $K$. lactis $H O$ pseudogene had not been described. We suggest that Mts1 directly induces switching, since two Mts1-binding sites in the MAT $\alpha$ locus were important. However, the Mts1 amino acid sequence does not suggest that Mts1 catalyzes DNA cleavage. We speculate that Mts1 may recruit $\alpha 3$ or other factors to the MAT loci to facilitate DNA cleavage. Interestingly, the transcription of Mts1 was repressed by the a/ $\alpha$-cell type and nutrients. The cell type regulation is similar to the regulation of $H O$ transcription in $S$. cerevisiae, limiting switching to haploid cells. The nutrient regulation of MTS1 explains an early observation (Herman and Roman 1966) that showed that switching in $K$. lactis only occurred in nutrient-limited media. Recent observations indicate that the RAS/cAMP pathway is responsible for the nutrient regulation of MTS1 transcription (E Barsoum and S Åström, unpubl.). We suggest that this is an adaptation to the fact that the diplophase is unstable in $K$. lactis. If a clone of haploid cells is deprived of nutrients, some cells in the population must switch mating type prior to mating, meiosis, and spore formation. The induction of MTS1 transcription in nutrientlimited conditions may facilitate this development.

We obtained preliminary data indicating that other yeast species may share a switching mechanism with $K$. lactis. We explored the closest relatives to $K$. lactis, collectively known as clade 11 (Kurtzman 2003; Lachance 2007), for the presence of $\alpha 3$-like sequences. Because Kluyveromyces dobzhanskii contained an $\alpha 3$-like gene whose size was altered (possibly circularized) in response to K. lactis Mts1 overexpression, it was likely to use a similar mechanism (data not shown). An $\alpha 3$ probe also hybridized to DNA from Kluyveromyces wickerhamii and Kluyveromyces marxianus. Hence, several other ascomycetes may have a similar mating type switching mechanism.

\section{The role of $\alpha 3$ in mating type switch}

According to a theoretical model by Hickey (1982), spread of TEs in a population depends on sexual reproduction. Definitive empirical evidence for this model is difficult to obtain, but asexuals and self-fertilizing sexuals appear to contain fewer TEs in their genomes than obligate sexually reproducing organisms (Wright and Finnegan 2001). One prediction of this model is that a TE that caused the host to reproduce sexually should be successfully transmitted. Therefore, once established at the MAT $\alpha / H M L \alpha$ loci, a TE that reintroduced a complete sexual cycle to its host would favor its own spread through the population. The $\alpha 3$ gene described in this study fits this model. We suggest a two-step model for MAT $\alpha$-to-MATa switching in

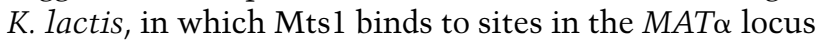
and facilitates $\alpha 3$-dependent excision of the MAT $\alpha 3$ gene (Fig. 8). We assume that the $\alpha 3$ gene circles are passively lost in subsequent cell cycles. Supporting this notion, we never observed $\alpha 3$ transposition or detected $\alpha 3$ remnants elsewhere in the K. lactis genome. The observation that the $\alpha 3$ gene circle junctions were important for switching from MAT $\alpha$ to MATa strongly indicates that the DNA lesions generated during MAT 3 mobilization were essential switching intermediates. We propose that the $\alpha 3$ gene circle junctions are required for proper 
A

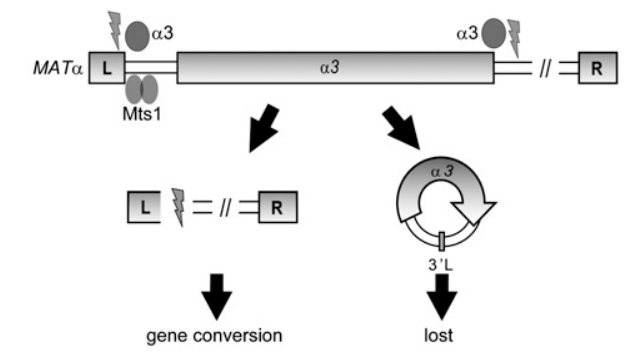

B

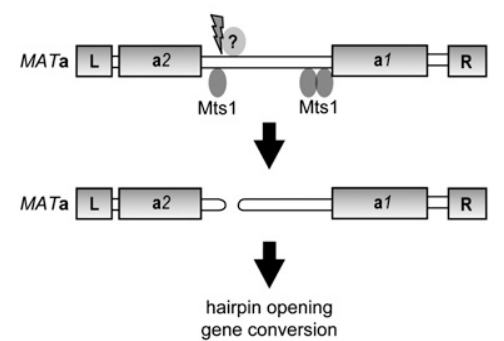

Figure 8. Model for mating-type switch in K. lactis. (A) In MAT $\alpha$ cells, binding of Mts1 to two sites close to the L repeat is important to induce switching. The $\alpha 3$ transposase-like protein presumably acts at sites flanking the MAT $\alpha 3$ gene, resulting in excision of an $\alpha 3$ gene circle. The circles are lost in subsequent cell cycles, as they lack an origin of replication. The resulting DNA lesions are channeled into a gene conversion pathway, in which the repetitive $\mathrm{L}$ and $\mathrm{R}$ sequences, present also at the $H M R \mathbf{a}$ locus, act as blocks of homology to resolve the recombination intermediates. (B) In MATa cells, binding of Mts1 to several sites in the MATa1-MATa2 intergenic region induces switching. An unknown protein generates a hairpin-capped DSB. The hairpin is opened in an Mrel1-dependent manner, and the DSB induces a gene conversion using the $H M L \alpha$ locus as donor sequence.

binding/activity of $\alpha 3$. The resulting DNA lesions are then channeled into a gene conversion pathway in which the $H M R$ a sequence is copied into the MAT locus. Consistent with this view, switching in $K$. lactis requires the recombination proteins $\operatorname{Rad} 51$ and $\operatorname{Rad} 52$ (Fig. 1E; data not shown).

It is intriguing that $H M L \alpha 3$ is essential for mating type switch, but $M A T \alpha 3$ is not. That $H M L \alpha 3$ escapes silencing is obvious, which was expected since we observed previously that both MAT $\alpha 3$ and $H M L \alpha 3$ are expressed (Åström et al. 2000). We hypothesize that the MAT $\alpha 3$ gene is not expressed during switching. This idea is based on the observation that expression of GFP- $\alpha 3$ from an ectopic promoter can complement the switching defect of a MAT $h m l \alpha 3 \Delta$ strain. Alternatively, if $\alpha 3$ is unstable and has a late role in the switching process, then this may explain the dependence on $H M L \alpha 3$.

\section{Similarities between mating type switch and $V(D) J$ recombination}

During $\mathrm{V}(\mathrm{D}) \mathrm{J}$ recombination, hairpin intermediates are formed at the end of coding segments (Roth et al. 1992). The resolution of these hairpins, followed by joining of two coding segments, generates the recombined immu- noglobulin gene. The Rag1 and Rag2 proteins are responsible for generating the hairpins during $\mathrm{V}(\mathrm{D}) \mathrm{J}$ recombination. In K. lactis, we observe a hairpin-capped DSB in a MATa mre11s strain, but not in a wild-type strain or

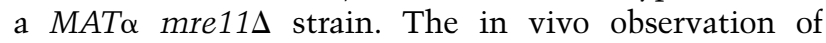
hairpins during $\mathrm{V}(\mathrm{D}) \mathrm{J}$ recombination was made in thymocytes from SCID mice (Roth et al. 1992), which are compromised in nonhomologous end-joining (NHEJ). Hence, in both cases, the presence of hairpins appears to be transient, and defects in DNA repair proteins stabilize them. The inability of the mre11s strain to process hairpins is consistent with observations that the $\operatorname{MRX}(\mathrm{N})$ [Mre11/Rad50/Xrs2(Nbs1)] complex from both yeast and humans exhibits manganese-dependent cleavage of hairpin structures in vitro (Paull and Gellert 1998; Trujillo and Sung 2001). It was shown previously in S. cerevisiae that MRX and Sae2 process hairpin intermediates, thereby preventing genome rearrangements (Lobachev et al. 2002). In this study, the hairpins were formed at long inverted repeats (IR) consisting of human Alu sequences, and the IRs were in fact responsible for DSB induction. The longest IR in the MATa1-MATa2 intergenic region was only $7 \mathrm{bp}$. We therefore suggest that hairpin formation in the MATa1-MATa2 intergenic region is independent of long IRs similar to the transesterification reaction performed by Rag1/2 (Roth et al. 1992; McBlane et al. 1995). The hairpin intermediate was not stabilized by an N-terminal phosphoesterase mutation (mre11D19A), suggesting that the resulting protein was able to process the hairpin. The corresponding mutant in S. cerevisiae (mre11D16A) produces a protein with a severe defect in the exonuclease activity of Mre11 (Lewis et al. 2004). A K. lactis mre11D19A mutant strain is methyl methanesulfonate (MMS)-sensitive, similar to an $S$. cerevisiae mre11D16A mutant strain, suggesting that the $K$. lactis mre11D19A allele is also defective in exonuclease activity. We surmise that Mre11 exonuclease activity is not important for opening the hairpin, but that another function of Mre11 performs this task. Alternatively, another nuclease, such as Sae2, performs the actual hairpin opening, as suggested in S. cerevisiae (Lengsfeld et al. 2007). It should be noted, however, that Mre11D19A could not complete the switching process from MATa to MAT $\alpha$, indicating that Mre11 exonuclease activity performs an important function during the process.

Mating type switch from MAT $\alpha$ to MATa requires the $H M L \alpha 3$ gene, but switching from MATa to MAT $\alpha$ did not. Therefore, in the MATa locus, DNA lesions must arise independently of $\alpha 3$ (Fig. 8). We hypothesize that the enzymes that generate lesions in MATa form hairpins, which are stabilized in the absence of Mre11. As the only known enzymes that generate hairpins after DNA cleavage are transposases (Zhou et al. 2004) or their derivatives (Roth et al. 1992), the unidentified enzymes that generate lesions in MATa may be related to transposases.

We did not observe DSBs in the MAT locus during switching in wild-type $K$. lactis strains. In addition, alkaline gels did not reveal any single-stranded lesions in the $M A T$ region (data not shown). The GAL1-10 promoter used to drive Mtsl expression is leaky in glucose-containing 
medium in $K$. lactis. The result is that switching is not synchronously induced, which may provide an explanation for the lack of an observed DSB. It is also feasible that the DNA lesions are very transient. The lesions may be introduced in a synaptic complex (Polard and Chandler 1995), a protein-DNA assembly in which the donor and acceptor sites are correctly aligned, as shown for $\mathrm{V}(\mathrm{D}) \mathrm{J}$ recombination and number of transposons (Curcio and Derbyshire 2003). Cutting the acceptor sites is almost immediately followed by strand invasion of the donor, limiting the time a DNA lesion can be observed. In models incorporating a synaptic complex, the sequences of both the donor and acceptor loci contribute to successful transposition. However, during switching in K. lactis, we never observed a mutation in the donor sequences that reduce switching. In the MAT $\alpha$ hra $\Delta$ strain, for example, in which the entire $H M R \mathbf{a}$ locus was deleted except for the $\mathrm{L}$ and $\mathrm{R}$ sequences, $\operatorname{mata} \Delta$ strains were generated efficiently upon Mts1 overexpression. Based on these findings, we find it unlikely that synaptic complexes are essential intermediates during switching in K. lactis.

Finally, preliminary evidence suggests that switching is directional in K. lactis (Supplemental Fig. S2). Whether or not the mechanism is similar to $S$. cerevisiae remains unknown, but will be the subject of future studies.

In summary, we show that an element similar to TEs directs mating type switch in $K$. lactis. Our observations are consistent with the idea that this TE was fixed in the $K$. lactis genome by aiding host sexuality.

\section{Materials and methods}

\section{Yeast strains}

The yeast strains used in this study are listed in Supplemental Table S1. Gene disruptions/deletions/fusions relied on homologous recombination using either a one-step (Kegel et al. 2006) or a two-step (Orr-Weaver et al. 1981) method. The one-step gene disruption procedure used kanMX or NAT PCR fragments amplified from pFA6a-KANMX (Bahler et al. 1998) or pAG25 (Goldstein and McCusker 1999). Genomic manipulations were confirmed by DNA blots or genomic PCR. Sequences of oligonucleotides used are available on request. SAY1346 (hmla3s::NAT) and SAY1348 $(h m l \alpha 3 \Delta:: \operatorname{kanMX})$ were generated by transforming the appropriate PCR fragment into SAY572 (nej1 $:: L E U 2)$, selecting for nourseothricin $(90 \mu \mathrm{g} / \mathrm{mL}$; CloNat) or Geneticin $(200 \mu \mathrm{g} / \mathrm{mL})$ resistance. Strains SAY1351 (MATa hml $3 \Delta:: N A T)$ and SAY1446

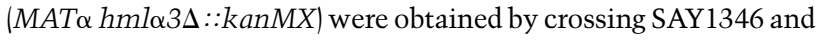
SAY1348 with a MAT $\alpha$ strain. Strains SAY726 (hmra $\Delta:: N A T)$ and SAY727 (mata $\triangle:: N A T)$, in which the entire sequence between the $\mathrm{L}$ and $\mathrm{R}$ repeats were deleted at $H M R \mathbf{a}$ and MATa, respectively, were generated by the one-step procedure. Generation of SAY990 $($ mata2 $2:: N A T)$ and SAY1003 (mata1 $1:: N A T)$ used the same procedure, but in these strains only the MATa1 or MATa2 ORFs (from the start codon to the stop codon) were deleted. SAY973 (mre11D19A) was generated as follows: Plasmid pJ18 was linearized with BamHI and introduced into CK213 by selecting for uracil prototrophs. The URA3 gene was popped out on 5-fluoroorotic acid (5-FOA), and the segregants were screened for the mre11D19A mutation using genomic PCR, followed by DNA sequencing. SAY1351 was transformed with pPMB35 (pGALMTS1), and the plasmid was selected against on 5-FOA. Segregants in which a mating type switch event occurred were

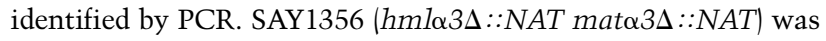

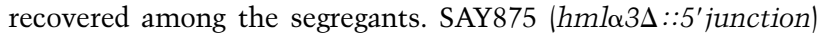
and SAY876 (hmla3s::3'junction) were generated by transforming MunI-linearized p648 or PacI-linearized p650 into CK213-4C, respectively, selecting for Uracil prototrophs and a pop-out procedure. SAY1194 (mat $\alpha 3 \Delta:: 3^{\prime}$ junction) was obtained through the introduction of pGAL-MTS1 into SAY876, as described above. SAY754 (mts1 $1:$ LEU2) was generated by introducing a BamHIPstI DNA fragment from pCXJ10-mts1 $1:$ LEU2 into AKY125 (lig4వ::kanMX), selection for $\mathrm{Leu}^{+}$isolates, and a cross with

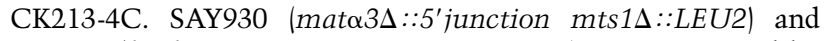

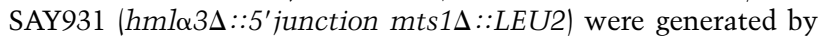
crossing SAY875 with SAY754 (mts1 $1:$ LEU2) containing pGALMTS1. SAY688 (mat $\alpha 1 \alpha 2 \Delta:: L E U 2)$ was generated by transforming SAY119 with PacI-linearized p392, selecting for uracil prototrophs, followed by the pop-out procedure. Strain SAY988 (MTS1-TAP), in which a TAP tag was fused to the $\mathrm{C}$ terminus of Mts1, was generated as described (Puig et al. 2001) by transforming strain SAY572 (nej1 $:: L E U 2)$ with the appropriate PCR fragment. SAY1377 and SAY1378 (mat $\Delta 20$ ), carrying deletions of the two Mts1-binding sites residing close to the $L$ repeat in the MAT $\alpha$ locus, were generated by transforming SAY509 (MAT $\alpha$ nej1 $:: L E U 2)$ with HpaI-linearized pEB85, followed by a pop-out procedure.

\section{Genetic selection}

The genetic selection in which the MTS1 alleles were isolated was performed as follows: SAY130 (hmla1s::kanMX) was transformed with pRS405-pApG using the lithium acetate method. Prior to transformation, pRS405-pApG was linearized in between the ADH1 and GPD1 promoters using BamHI. Among $7 \times 10^{4}$ transformed colonies, we isolated 39 stable $\mathrm{G}^{418}$-resistant strains. For allelism tests, the revertants were crossed to SAY119 and tetrad analysis was performed. Cosegregation of $\mathrm{G}^{418}$ resistance and $\mathrm{Leu}^{+}$indicated that the plasmid insertion was allelic to the mutation that caused $\mathrm{G}^{418}$ resistance, a criterion that 27 isolates satisfied. For determining the exact locations of the pRS405pApG insertions, we performed inverse PCR. Five micrograms of genomic DNA from the revertant strains were digested with MspI for $1 \mathrm{~h}$ at $37^{\circ} \mathrm{C}$, heat-inactivated for $20 \mathrm{~min}$ at $65^{\circ} \mathrm{C}$, and diluted 10 -fold in $1 \times$ ligase buffer, and $1 \mathrm{U}$ of T4 DNA ligase was added. After ligation, the DNA was precipitated, lyophilized, and resuspended in $20 \mu \mathrm{L}$ of water. One microliter of this mixture was PCR-amplified using ADH1 primer pairs 549 (5' -CTATCAAGT ATAAATAGACCTGC-3') and 554 (5'-GGAAGGCCGTATACC GTTG-3') and GPD1 primer pairs 550 (5'-GAGTGAAACTG TTACGTTACC-3') and 555 (5'-CGAAACTGCCAATACCAAG C-3'), thus generating PCR fragments with DNA flanking the insertion point of pRS405-pApG. The PCR fragments were sequenced (Macrogen), and the sequences were compared with the K. lactis genomic sequence (http://cbi.labri.fr/Genolevures). The MTS1-1, MTS1-2, and MTS1-3 strains had plasmid insertions at $-324,-351$, and -709 relative to the MTS1 start codon, respectively. Six of the isolated strains had independent insertions of pRS405-pApG in the SIR2 ORF. The remaining 18 isolates will be presented elsewhere.

\section{Plasmids}

Cloning was performed using standard methods (Sambrook and Russell 2001). For details, please see the Supplemental Material.

\section{Methods}

DNA/RNA/protein blots, DNA/RNA/protein preparations, and transformation of yeast and Escherichia coli followed standard 
protocols (Schiestl and Gietz 1989; Ausubel 1999; Sambrook and Russell 2001). Yeast media was prepared as described (Burke et al. 2000). EMSAs were performed as described (Sjöstrand et al. 2002) using $\sim 10$ ng of partially purified maltose-binding protein (MBP)/Mts1 in each reaction. The two probes showing a specific mobility shift corresponded to sequences $37-185$ bp upstream of the $\mathbf{a} 2$ ORF and 1-131 bp upstream of the a1 ORF. Recombinant MBP-Mts1 was partially purified and digested with factor Xa using the procedure recommended by the manufacturer (New England Biolabs). Site-directed mutagenesis was performed according to the protocol outlined in the Stratagene QuickChange procedure. For DNA/RNA blots, ${ }^{32} \mathrm{P}$-labeled probes were used and quantified when indicated using a PhosphorImager (Fuji). $\lambda$-Exonuclease digestion of genomic DNA was performed for $15 \mathrm{~min}$ at $37^{\circ} \mathrm{C}$ using the buffer supplied by the manufacturer (New England Biolabs). For protein blots, the anti-TAP primary antibody (Invitrogen) was diluted 1:500 and the anti-GFP antibody (Clontech) was diluted 1:1000. Mating type-specific PCR used primer sets $193\left(5^{\prime}\right.$-CCAATTCAAAATTGCTACCC-3') and 553 (5'-GTCAAGCGCCTTGTCCAATG-3') for MATa and 551 (5'-CCTTGATGAACTCAGTCTGAG-3') and 553 for MAT $\alpha$. Amplifications used standard conditions with an annealing temperature of $55^{\circ} \mathrm{C}$.

\section{Acknowledgments}

We thank S. Carter, M. Mannervik, and P. Ljungdahl for critical reading of the manuscript, and members of the laboratory for helpful suggestions. This work was supported by grants from the Swedish Research Council and the Swedish Cancer Society to S.U.A.

\section{References}

Altschul SF, Madden TL, Schaffer AA, Zhang J, Zhang Z, Miller W, Lipman DJ. 1997. Gapped BLAST and PSI-BLAST: A new generation of protein database search programs. Nucleic Acids Res 25: 3389-3402.

Åström SU, Kegel A, Sjöstrand JO, Rine J. 2000. Kluyveromyces lactis Sir2p regulates cation sensitivity and maintains a specialized chromatin structure at the cryptic $\alpha$-locus. Genetics 156: 81-91.

Ausubel FM. 1999. Short protocols in molecular biology: A compendium of methods from current protocols in molecular biology. Wiley, New York.

Babu MM, Iyer LM, Balaji S, Aravind L. 2006. The natural history of the WRKY-GCM1 zinc fingers and the relationship between transcription factors and transposons. Nucleic Acids Res 34: 6505-6520.

Bahler J, Wu JQ, Longtine MS, Shah NG, McKenzie A III, Steever AB, Wach A, Philippsen P, Pringle JR. 1998. Heterologous modules for efficient and versatile PCR-based gene targeting in Schizosaccharomyces pombe. Yeast 14: 943951.

Burke D, Dawson D, Stearns T. 2000. Methods in yeast genetics: A Cold Spring Harbor Laboratory course manual. Cold Spring Harbor Laboratory Press, Cold Spring Harbor, NY.

Butler G, Kenny C, Fagan A, Kurischko C, Gaillardin C, Wolfe KH. 2004. Evolution of the MAT locus and its Ho endonuclease in yeast species. Proc Nat1 Acad Sci 101: 1632-1637.

Byrne KP, Wolfe KH. 2005. The Yeast Gene Order Browser: Combining curated homology and syntenic context reveals gene fate in polyploid species. Genome Res 15: 1456-1461.

Curcio MJ, Derbyshire KM. 2003. The outs and ins of transposition: From mu to kangaroo. Nat Rev Mol Cell Biol 4: 865-877.
Doolittle WF, Sapienza C. 1980. Selfish genes, the phenotype paradigm and genome evolution. Nature 284: 601-603.

Fabre E, Muller H, Therizols P, Lafontaine I, Dujon B, Fairhead C. 2005. Comparative genomics in hemiascomycete yeasts: Evolution of sex, silencing, and subtelomeres. Mol Biol Evol 22: 856-873.

Feschotte C, Pritham EJ. 2007. DNA transposons and the evolution of eukaryotic genomes. Annu Rev Genet 41: 331-368.

Fraser JA, Diezmann S, Subaran RL, Allen A, Lengeler KB, Dietrich FS, Heitman J. 2004. Convergent evolution of chromosomal sex-determining regions in the animal and fungal kingdoms. PLoS Biol 2: e384. doi: 10.1371/journal. pbio.0020384.

Goldstein AL, McCusker JH. 1999. Three new dominant drug resistance cassettes for gene disruption in Saccharomyces cerevisiae. Yeast 15: 1541-1553.

Haber JE. 1998. Matin type gene switching in Saccharomyces cerevisiae. Annu Rev Genet 32: 561-599.

Haren L, Ton-Hoang B, Chandler M. 1999. Integrating DNA: Transposases and retroviral integrases. Annu Rev Microbiol 53: $245-281$.

Herman A, Roman H. 1966. Allele specific determinants of homothallism in Saccharomyces lactis. Genetics 53: 727-740.

Herskowitz I. 1988. Life cycle of the budding yeast Saccharomyces cerevisiae. Microbiol Rev 52: 536-553.

Herskowitz I, Rine J, Strathern JN. 1992. Mating type determination and matin type interconversion in Saccharomyces cerevisiae. In The molecular and cellular biology of the yeast Saccharomyces (ed. EW Jones et al.), pp. 583-656. Cold Spring Harbor Laboratory Press, New York, NY.

Hickey DA. 1982. Selfish DNA: A sexually-transmitted nuclear parasite. Genetics 101: 519-531.

Hull CM, Johnson AD. 1999. Identification of a mating type-like locus in the asexual pathogenic yeast Candida albicans. Science 285: 1271-1275.

Jones JM, Gellert M. 2004. The taming of a transposon: V(D)J recombination and the immune system. Immunol Rev 200: 233-248.

Juretic N, Hoen DR, Huynh ML, Harrison PM, Bureau TE. 2005. The evolutionary fate of MULE-mediated duplications of host gene fragments in rice. Genome Res 15: 1292-1297.

Kapitonov VV, Jurka J. 2005. RAG1 core and V(D)J recombination signal sequences were derived from Transib transposons. PLOS Biol 3: e181. doi: 10.1371/journal.pbio.0030181.

Kegel A, Martinez P, Carter SD, Åström SU. 2006. Genome wide distribution of illegitimate recombination events in Kluyveromyces lactis. Nucleic Acids Res 34: 1633-1645.

Kulkosky J, Jones KS, Katz RA, Mack JP, Skalka AM. 1992. Residues critical for retroviral integrative recombination in a region that is highly conserved among retroviral/retrotransposon integrases and bacterial insertion sequence transposases. Mol Cell Biol 12: 2331-2338.

Kurtzman CP. 2003. Phylogenetic circumscription of Saccharomyces, Kluyveromyces and other members of the Saccharomycetaceae, and the proposal of the new genera Lachancea, Nakaseomyces, Naumovia, Vanderwaltozyma and Zygotorulaspora. FEMS Yeast Res 4: 233-245.

Lachance MA. 2007. Current status of Kluyveromyces systematics. FEMS Yeast Res 7: 642-645.

Lander ES, Linton LM, Birren B, Nusbaum C, Zody MC, Baldwin J, Devon K, Dewar K, Doyle M, FitzHugh W, et al. 2001. Initial sequencing and analysis of the human genome. Nature 409: 860-921.

Lengeler KB, Fox DS, Fraser JA, Allen A, Forrester K, Dietrich FS, Heitman J. 2002. Matin type locus of Cryptococcus 
neoformans: A step in the evolution of sex chromosomes. Eukaryot Cell 1: 704-718.

Lengsfeld BM, Rattray AJ, Bhaskara V, Ghirlando R, Paull TT. 2007. Sae2 is an endonuclease that processes hairpin DNA cooperatively with the Mre11/Rad50/Xrs2 complex. Mol Cell 28: 638-651.

Lewis LK, Storici F, Van Komen S, Calero S, Sung P, Resnick MA. 2004. Role of the nuclease activity of Saccharomyces cerevisiae Mre11 in repair of DNA double-strand breaks in mitotic cells. Genetics 166: 1701-1713.

Lin R, Ding L, Casola C, Ripoll DR, Feschotte C, Wang H. 2007. Transposase-derived transcription factors regulate light signaling in Arabidopsis. Science 318: 1302-1305.

Lobachev KS, Gordenin DA, Resnick MA. 2002. The Mre11 complex is required for repair of hairpin-capped doublestrand breaks and prevention of chromosome rearrangements. Cell 108: 183-193.

Malone RE, Esposito RE. 1980. The RAD52 gene is required for homothallic interconversion of mating types and spontaneous mitotic recombination in yeast. Proc Natl Acad Sci 77: 503-507.

McBlane JF, van Gent DC, Ramsden DA, Romeo C, Cuomo CA, Gellert M, Oettinger MA. 1995. Cleavage at a V(D)J recombination signal requires only RAG1 and RAG2 proteins and occurs in two steps. Cell 83: 387-395.

Orr-Weaver TL, Szostak JW, Rothstein RJ. 1981. Yeast transformation: A model system for the study of recombination. Proc Natl Acad Sci 78: 6354-6358.

Paull TT, Gellert M. 1998. The 3' to $5^{\prime}$ exonuclease activity of Mre 11 facilitates repair of DNA double-strand breaks. Mol Cell 1: 969-979.

Polard P, Chandler M. 1995. An in vivo transposase-catalyzed single-stranded DNA circularization reaction. Genes \& Dev 9: 2846-2858.

Puig O, Caspary F, Rigaut G, Rutz B, Bouveret E, BragadoNilsson E, Wilm M, Seraphin B. 2001. The tandem affinity purification (TAP) method: A general procedure of protein complex purification. Methods 24: 218-229.

Ramsden DA, Gellert M. 1995. Formation and resolution of double-strand break intermediates in $\mathrm{V}(\mathrm{D}) \mathrm{J}$ rearrangement. Genes \& Dev 9: 2409-2420.

Roth DB, Menetski JP, Nakajima PB, Bosma MJ, Gellert M. 1992. V(D)J recombination: Broken DNA molecules with covalently sealed (hairpin) coding ends in scid mouse thymocytes. Cell 70: 983-991.

Sambrook J, Russell DW. 2001. Molecular cloning: A laboratory manual. Cold Spring Harbor Laboratory Press, Cold Spring Harbor.

Schiestl RH, Gietz RD. 1989. High efficiency transformation of intact yeast cells using single stranded nucleic acids as a carrier. Curr Genet 16: 339-346.

Shimizu M, Li W, Covitz PA, Hara M, Shindo H, Mitchell AP. 1998. Genomic footprinting of the yeast zinc finger protein Rmelp and its roles in repression of the meiotic activator IME1. Nucleic Acids Res 26: 2329-2336.

Sjöstrand JO, Kegel A, Åström SU. 2002. Functional diversity of silencers in budding yeasts. Eukaryot Cell 1: 548-557.

Sundaresan V, Freeling M. 1987. An extrachromosomal form of the $M u$ transposons of maize. Proc Natl Acad Sci 84: 49244928.

Trujillo KM, Sung P. 2001. DNA structure-specific nuclease activities in the Saccharomyces cerevisiae Rad50*Mre11 complex. I Biol Chem 276: 35458-35464.

Tsong AE, Tuch BB, Li H, Johnson AD. 2006. Evolution of alternative transcriptional circuits with identical logic. $\mathrm{Na}$ ture 443: 415-420.
Wright S, Finnegan D. 2001. Genome evolution: Sex and the transposable element. Curr Biol 11: R296-R299. doi: 10.1016/ S0960-9822(01)00168-3.

Zhou L, Mitra R, Atkinson PW, Hickman AB, Dyda F, Craig NL. 2004. Transposition of $h A T$ elements links transposable elements and V(D)J recombination. Nature 432: 995-1001. 


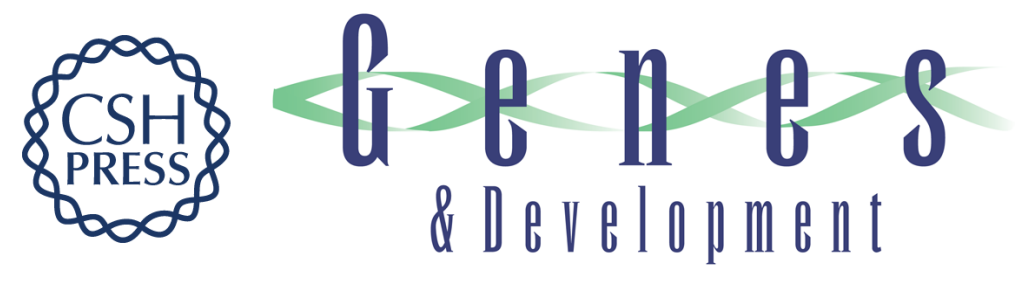

\section{$\alpha 3$, a transposable element that promotes host sexual reproduction}

Emad Barsoum, Paula Martinez and Stefan U. Åström

Genes Dev. 2010, 24: originally published online December 15, 2009

Access the most recent version at doi:10.1101/gad.557310

\footnotetext{
Supplemental http://genesdev.cshlp.org/content/suppl/2009/12/03/gad.557310.DC1

Material

Related Content Switching the mechanism of mating type switching: a domesticated transposase supplants a domesticated homing endonuclease

Laura N. Rusche and Jasper Rine

Genes Dev. January , 2010 24: 10-14

References This article cites 47 articles, 15 of which can be accessed free at:

http://genesdev.cshlp.org/content/24/1/33.full.html\#ref-list-1

Articles cited in:

http://genesdev.cshlp.org/content/24/1/33.full.html\#related-urls

License

Email Alerting Receive free email alerts when new articles cite this article - sign up in the box at the top Service right corner of the article or click here.
}

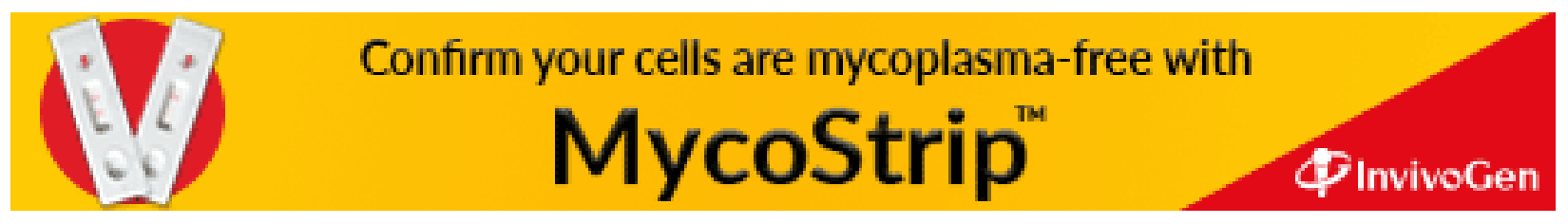

